\title{
Innovation of Fuel Maps and Pre-Ignition Maps of Experimental Vehicle as a Part of Development for Control Algorithm of the HCCl Engine
}

\author{
Michal Puškár ${ }^{1, *}$, Melichar Kopas ${ }^{1}$, Dušan Puškár ${ }^{1}$, Ján Lumnitzer ${ }^{1}$ \\ ${ }^{1}$ Faculty of Mechanical Engineering, TU Košice, Letná 9, 04001 Košice, Slovak republic
}

\begin{abstract}
The questions concerning fuel consumption and emissions of the motor cars is always topical with regard to increasingly stricter technical standards that are valid within the automotive industry. Application of an innovative combustion technology, which is known as the Homogenous Charge Compression Ignition (HCCl) offers a possible answer for a suitable solution of the above-mentioned problems. Combustion of the homogenous mixture runs at the same time in the whole combustion area of the cylinder, i.e. almost the whole volume of the fuel-air mixture is combusted. In this way is possible not only to save a fuel, but also to reduce engine emissions. However, application of the $\mathrm{HCCl}$ technology is connected with some basic technical problems because the self-ignition process is very complicated and demanding with regard to the process control. This article analyses the engine fuel maps and pre-ignition maps in order to quantify their influence on the fuel consumption and on the emission production. This research work is directly related to development of a control algorithm determined for the $\mathrm{HCCl}$ engine.
\end{abstract}

Keywords: combustion engine, fuel map, pre-ignition map, HCCl technology.

\section{Introduction}

It is a well-known fact that reduction of the fossil fuel resources, together with a necessity to make operation of the piston combustion engines more ecological, is a very serious worldwide problem. In spite of a fact that there are introduced new, alternative solutions of the driving systems, the standard piston combustion engine remains the most often used kind of driving unit, which is determined for the road transport applications and for a large category of the ships, too.

Improvement of the piston combustion engine efficiency and elimination of the ecological disadvantages is possible by means of a specific motor-management system using the data field changes implemented within the engine control unit. Modification of the engine control system is possible after editing of the individual data field sections in order to achieve partial changes in the individual engine speed spectra. The control system of the driving unit consists of algorithms operating with specific and complex data interrelationships, whereas the control unit software is based on numerical combinations.

\section{Material and Methods}

\subsection{Control system of driving unit}

The correct operation of the combustion engine control unit requires a continuous flow of the input signals. Today there are applied control units functioning according 
to the complicated control algorithms. The more these algorithms are complex, the larger amount of the actual parameters has to be distributed. The input values are measured by means of the sensors placed directly on the combustion engine and consequently these values are processed and evaluated by the control unit.

Taking into consideration a principle of functionality, the control unit can be characterised and described as a multifunctional control microcomputer, whereas the main task of it is receiving of the input data and following processing of them. The control unit performs a correction of the volume and length of the injected fuel charge in order to optimise the engine power output parameters as well as to reach favourable fuel consumption and low-level emission values [1, 2].

Optimisation of the fuel-air mixture ignition in the combustion engine is another important activity of the control unit. It is necessary to pay attention to the ignition system during solution of the whole motor-management system. Especially the highspeed spark ignition engines are very sensitive to the exact moment of the fuel mixture ignition $[3,4]$.

The moment of ignition in the case of the standard spark ignition engines is determined with regard to the optimal fuel consumption and emission reduction. On the other side, situation in the case of the racing car engines is different, because such kinds of engines are oriented towards the maximal engine operational efficiency. The most important factors influencing correctness of the ignition process are: the engine temperature, the temperature and composition of the exhaust gases, the suction air temperature etc. These factors must be taken into consideration during formation of the data fields specified for the control unit. The optimal ignition maps are created using a mathematical simulation of the pre-ignition, as well [5].

\subsection{Experimental model and measuring equipment}

Modification of the data fields was performed by means of specific software [6]. Proposal of the data fields was realised on the real driving unit installed in the experimental vehicle, which is especially designed for the international competition Shell Eco-marathon. Namely it is the four-stroke piston combustion engine HONDA of type GX25 with the engine performance characteristics presented in Fig.1

The TCl system (Transistor Coil Ignition) originally installed in the experimental engine was replaced by the complex EFI system (Electronic Fuel Injection) from the company Ecotrons (Fig.2). This new system is applied as a complex set intended for the smallvolume engines. The system control module enables managing of the ignition and injection system, together with recording of the engine operational data.

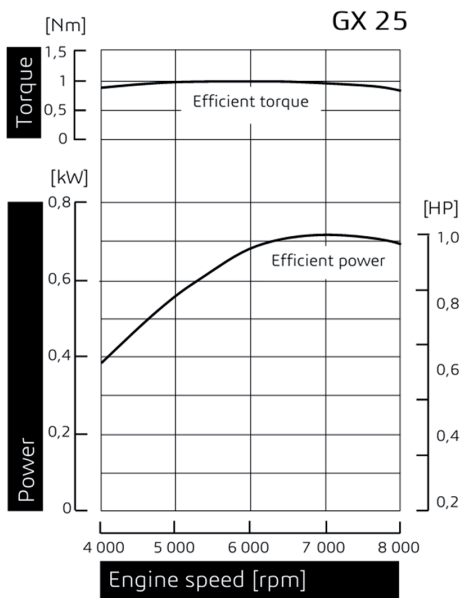

Fig. 1: Performance characteristics of the experimental engine.

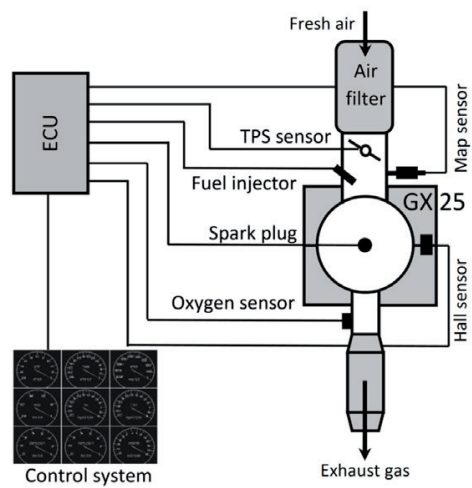

Fig. 2: Application of the EFI system for the experimental engine.

The sensors installed in the injection module are sensing data necessary for a correct operation of the control unit [6]. Thanks to the data obtained from the measuring process it is possible to operate with the real values in order to modify the control unit data fields. The $\lambda$-values measured by the exhaust gas oxygen sensor (lambda sensor) were obtained using the measuring equipment INOVATE MOTOSPORTS 3837 LM - 4.

\subsection{Creation of the individual data maps}

The individual data maps were created by 
means of the software product ProCal, which is an integrated part of the installed EFI system. This software enables on-line monitoring of the engine operational parameters, e.g. the engine speed $(\mathrm{rpm})$, the pressure in suction pipe $(\mathrm{kPa})$, the throttle position (\%), the $\lambda$-values etc. These input data are important for creation of the fuel maps and preignition maps in order to reach the best possible final effect.

After interconnection of the EFI control unit with the modification component $(\mathrm{PC})$ by means of the KDS interface the software ProCal displays such settings of the fuel maps and pre-ignition maps, which are typically used according to the recommendation from the producer Ecotrons with regard to the given engine [6]. Research and development of the new data maps are based on the above-mentioned standard settings (Tab.1, Fig. 3 and Tab.3, Fig. 4) that were optimised consequently.

\subsection{Innovation of the fuel map for the experimental engine}

Proposal of the fuel maps is based on the concrete design solution of the given driving unit. It is necessary to keep the suitable fuel-air mixture composition on various operational conditions during the whole optimisation process [7, 8].

Each of the motor-management software products describes the engine-loading status using information about a throttle position. This position is sensed by the Throttle Position Sensor (TPS), namely in the range from 0 to $100 \%$. Range of the engine loading can be also described by the value of suction pressure, which is generated in the suction pipe, whereas the Manifold Absolute Pressure (MAP) sensor is reading the under-pressure value.

However, the software ProCal, which was applied for creation of the driving unit fuel maps,

Table 1: Standard and modified fuel maps. is utilizing other, non-standard principle. Unlike the standard motor-management software products the software ProCal does not describe the actual loading of the driving unit by the throttle position and by the engine speed. The fuel map in this case is not created according to the above-mentioned two variables and length of the injector impulse, because creation of the fuel maps is influenced by the various factors, for example by the altitude above sea level, the air temperature, the vehicle speed etc. Therefore, the software ProCal automatically recalculates the variable value "LOAD" according to the ratio TPS/rpm such that the value "LOAD" is a ratio between the real amount of suction air and the theoretical amount of it, whereas it is given in $\%$. Volume of the injected fuel is also given in \%; it is a ratio between the volumetric efficiency and the flow passing through the injection nozzle. It is necessary to know the engine volumetric efficiency in order to create the fuel map correctly, with regard to a fact that the volumetric efficiency is a decisive factor for determination of the fuel injection time interval. The highest volumetric efficiency of the given experimental engine is reached within the engine speed range from 6500 to $7500 \mathrm{rpm}$.

The injection system contains the solenoid injector of the type EFIJ. Proposal of the fuel map requires information about the value of the fuel volume flowing through the injector nozzle and about the fuel system pressure. In our case the flow volume of the applied injector was 80 g.min-1 and the fuel system pressure was $294 \mathrm{kPa}$.

The fuel map was developed on the assumption that it is necessary to reach the lean fuel-air mixture, namely with the $\lambda$-values from 1.07 to 1.20 . The original fuel map was applied as an initial base and the following procedure of data transcription was performed using the data table obtained from the

\begin{tabular}{|l|l|l|l|l|l|l|l|l|l|}
\hline \multicolumn{10}{|c|}{ Standard fuel map } \\
\hline TPS position [\%] & 0,000 & 6,000 & 12,000 & 18,000 & 24,000 & 30,000 & 36,000 & 42,000 & 48,000 \\
\hline Amount of injected fuel [\%] & 0,000 & 1,500 & 4,688 & 12,000 & 41,063 & 65,063 & 90,000 & 117,000 & 150,000 \\
\hline TPS position [\%] & 54,000 & 60,000 & 66,000 & 72,000 & 78,000 & 84,000 & 90,000 & 96,000 & 102,000 \\
\hline Amount of injected fuel [\%] & 171,000 & 189,938 & 207,000 & 222,938 & 231,938 & 245,063 & 257,063 & 261,938 & 266,063 \\
\hline \multicolumn{10}{|c|}{ Modified fuel map } \\
\hline TPS position [\%] & 0,000 & 6,000 & 12,000 & 18,000 & 55,008 & 57,000 & 63,000 & 67,992 & 72,000 \\
\hline Amount of injected fuel [\%] & 0,000 & 1,500 & 4,688 & 12,000 & 41,063 & 65,063 & 90,000 & 125,063 & 135,000 \\
\hline TPS position [\%] & 75,000 & 78,000 & 79,008 & 82,008 & 84,000 & 85,008 & 87,000 & 88,008 & 91,008 \\
\hline Amount of injected fuel [\%] & 138,000 & 140,063 & 143,063 & 144,000 & 146,063 & 146,063 & 147,000 & 147,938 & 149,063 \\
\hline
\end{tabular}




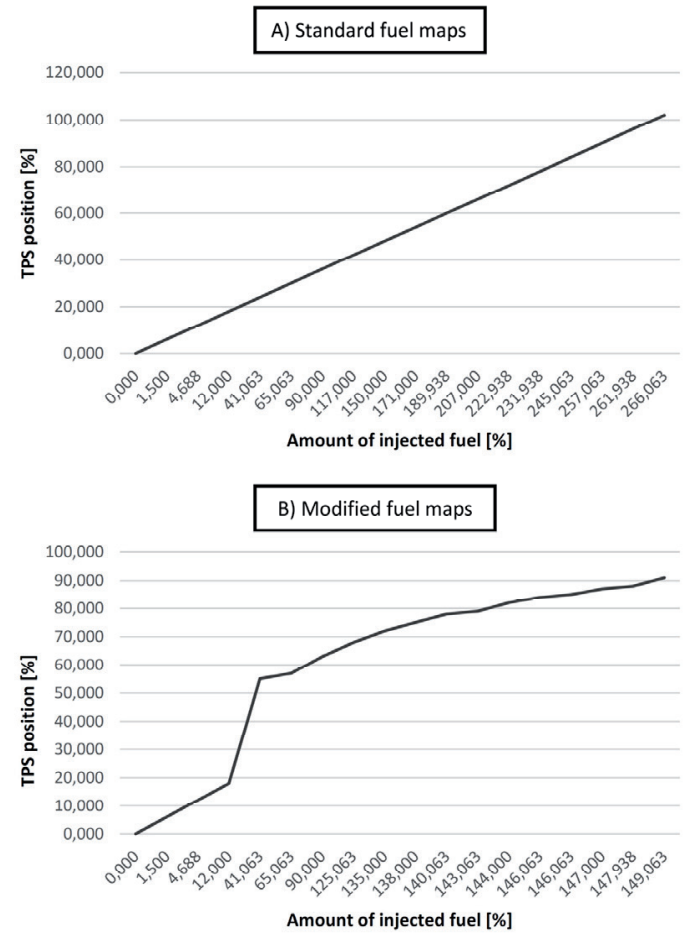

Fig. 2: Application of the EFI system for the experimental engine.

software ProCal, taking into consideration the final efficiency of the combustion process (Tab.1 and Fig.3).

The $\lambda$-values were measured and recorded in the intervals of every $500 \mathrm{rpm}$ within the whole engine speed spectrum after modification of the fuel map as well as after pre-programming of this fuel map into the control system. (Tab. 2). Consequently, there were performed the required corrections, namely it was necessary to reduce the fuel injection value in the rich mixture areas by a correction made in the concrete data field part.

2.5. Innovation of the pre-ignition map for the experimental engine

The applied software ProCal enables not only editing of the fuel map, but it also enables data changing in the pre-ignition map. Optimisation of the pre-ignition map is based on the engine design solution, because the real engine construction influences process of the fuel mixture combustion

Table 2: $\lambda$-values after modification of the data fields. in the engine combustion area. Combustion process of the fuel mixture is running very fast in the case of the small-volume engines. Therefore, it is necessary to dispose of a possibility to change the value of advanced ignition. The compression ratio of the tested driving unit is 8:1. This fact causes a fast running of the mixture combustion process, whereas the pre-ignition value is from $4^{\circ}$ to $20^{\circ}$ before the top dead centre. Another relevant factor, which influences behaviour of the mixture combustion, is the fuel octane number. It is a wellknown fact that higher value of the octane number also means a better fuel resistance to the detonation combustion [9].

The software ProCal is utilizing the next variable values: the throttle position, the engine speed and the ignition advance angle. Insomuch that the detonation combustion sensor is not a part of the injection module, so it is necessary to find the optimal ignition advance value.

Optimisation of the pre-ignition map, using the software ProCal, can be realised either by the data modification in the data table (Tab. 3) or by the changes made in the 2D or 3D coordinate system (Fig. 4).

The pre-ignition map was edited by changing of data in the data table (Tab. 4). The individual values can be changed from the plus values to the minus values.

The important part of the pre-ignition map is the engine speed area with the highest power output of the driving unit. The highest torque of the tested driving unit is recorded in the engine speed range from 6500 to 7500 rpm (Fig. 4).

\section{Results and Discussion}

The fuel consumption of the given piston combustion engine was determined according to the number of kilometres ridden with one litre of fuel. The correct variant of the motor-management modification was verified during the testing process. The individual measurements were repeated threetimes one after another and on the same weather conditions (the temperature, pressure and humidity of air) in order to obtain the reliable results. The engine was firstly tested with a standard (original)

\begin{tabular}{|l|c|c|c|c|c|c|c|c|c|c|c|}
\hline Engine speed $(\mathrm{rpm})$ & 4000 & 4500 & 5000 & 5500 & 6000 & 6500 & 7000 & 7500 & 8000 & 8500 \\
\hline 1st measuring $(\lambda)$ & 0,99 & 0,98 & 1 & 1,07 & 1,15 & 1 & 0,99 & 1,06 & 1,1 & 1,11 \\
\hline Final measuring $(\lambda)$ & 1,07 & 1,09 & 1,09 & 1,1 & 1,14 & 1,16 & 1,14 & 1,14 & 1,12 & 1,13 \\
\hline
\end{tabular}




\begin{tabular}{|c|c|c|c|c|c|c|c|}
\hline \multicolumn{8}{|c|}{ Standard ignition map } \\
\hline & & \multicolumn{6}{|c|}{ TPS position [\%] } \\
\hline & & 20,250 & 26,250 & 32,250 & 38,250 & 44,250 & 50,250 \\
\hline \multirow{16}{*}{ 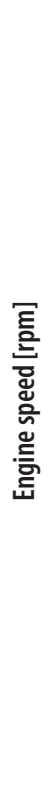 } & 1200,000 & 12,000 & 14,250 & 15,000 & 15,000 & 17,250 & 18,000 \\
\hline & 1680,000 & 14,250 & 15,000 & 15,000 & 15,750 & 18,000 & 20,250 \\
\hline & 1980,000 & 15,000 & 17,250 & 18,000 & 18,750 & 20,250 & 21,750 \\
\hline & 2460,000 & 18,000 & 18,750 & 21,750 & 21,750 & 21,750 & 20,250 \\
\hline & 3000,000 & 21,750 & 21,750 & 21,750 & 21,000 & 20,250 & 18,750 \\
\hline & 3540,000 & 21,750 & 20,250 & 20,250 & 20,250 & 18,750 & 18,750 \\
\hline & 4020,000 & 20,250 & 20,250 & 18,750 & 18,750 & 18,750 & 18,000 \\
\hline & 4500,000 & 18,750 & 18,750 & 18,750 & 18,000 & 18,000 & 18,000 \\
\hline & 4980,000 & 18,750 & 18,750 & 18,000 & 18,000 & 17,250 & 17,250 \\
\hline & 5520,000 & 18,000 & 18,000 & 15,750 & 15,750 & 15,750 & 15,750 \\
\hline & 6000,000 & 18,000 & 15,750 & 15,750 & 15,000 & 15,000 & 15,000 \\
\hline & 7020,000 & 15,750 & 15,000 & 15,000 & 14,250 & 14,250 & 14,250 \\
\hline & 7980,000 & 14,250 & 14,250 & 14,250 & 12,750 & 12,750 & 12,750 \\
\hline & 9000,000 & 12,750 & 12,750 & 12,750 & 12,750 & 12,750 & 12,000 \\
\hline & 10020,000 & 12,750 & 12,750 & 12,000 & 12,000 & 12,000 & 12,000 \\
\hline & 10200,000 & 12,000 & 12,000 & 12,000 & 12,000 & 12,000 & 12,000 \\
\hline \multirow{18}{*}{ 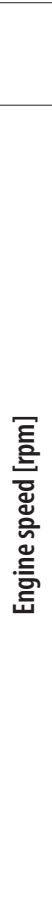 } & & \multicolumn{6}{|c|}{ TPS position [\%] } \\
\hline & & 56,250 & 62,250 & 68,250 & 74,250 & 80,250 & \\
\hline & 1200,000 & 18,750 & 20,250 & 21,750 & 21,750 & 21,000 & \\
\hline & 1680,000 & 21,000 & 21,000 & 21,750 & 21,000 & 21,000 & \\
\hline & 1980,000 & 21,750 & 21,750 & 21,000 & 21,000 & 18,750 & \\
\hline & 2460,000 & 20,250 & 18,750 & 18,750 & 18,750 & 18,000 & \\
\hline & 3000,000 & 18,750 & 18,750 & 18,750 & 18,000 & 18,000 & \\
\hline & 3540,000 & 18,000 & 18,000 & 18,000 & 17,250 & 17,250 & \\
\hline & 4020,000 & 18,000 & 18,000 & 17,250 & 17,250 & 15,750 & \\
\hline & 4500,000 & 17,250 & 17,250 & 17,250 & 15,750 & 14,250 & \\
\hline & 4980,000 & 15,750 & 15,750 & 15,750 & 14,250 & 14,250 & \\
\hline & 5520,000 & 15,000 & 15,000 & 14,250 & 14,250 & 12,750 & \\
\hline & 6000,000 & 14,250 & 14,250 & 14,250 & 12,750 & 12,750 & \\
\hline & 7020,000 & 12,750 & 12,750 & 12,750 & 12,000 & 12,000 & \\
\hline & 7980,000 & 12,750 & 12,000 & 12,000 & 12,000 & 12,000 & \\
\hline & 9000,000 & 12,000 & 12,000 & 12,000 & 12,000 & 11,250 & \\
\hline & 10020,000 & 12,000 & 12,000 & 11,250 & 11,250 & 9,750 & \\
\hline & 10200,000 & 11,250 & 11,250 & 10,500 & 9,750 & 9,750 & \\
\hline
\end{tabular}


Standard ignition map

\begin{tabular}{|c|c|c|c|c|c|c|c|}
\hline & & \multicolumn{6}{|c|}{ TPS position [\%] } \\
\hline & & 53,250 & 54,000 & 54,750 & 56,250 & 57,000 & 57,750 \\
\hline \multirow{16}{*}{ 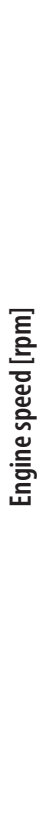 } & 780,000 & 9,000 & 9,000 & 9,000 & 9,000 & 9,000 & 9,000 \\
\hline & 1200,000 & 9,000 & 9,000 & 9,000 & 9,000 & 9,000 & 9,000 \\
\hline & 1980,000 & 9,000 & 9,000 & 9,000 & 9,000 & 9,000 & 9,000 \\
\hline & 2460,000 & 9,000 & 9,000 & 9,000 & 9,000 & 9,000 & 9,000 \\
\hline & 3000,000 & 15,000 & 15,000 & 15,000 & 15,000 & 15,000 & 15,000 \\
\hline & 3540,000 & 21,750 & 20,250 & 20,250 & 20,250 & 18,750 & 18,750 \\
\hline & 4020,000 & 20,250 & 20,250 & 18,750 & 18,750 & 18,750 & 18,000 \\
\hline & 4500,000 & 18,750 & 18,750 & 18,750 & 18,000 & 18,000 & 18,000 \\
\hline & 4980,000 & 18,750 & 18,750 & 18,000 & 15,000 & 15,750 & 15,750 \\
\hline & 5520,000 & 18,000 & 18,000 & 15,750 & 15,750 & 14,250 & 14,250 \\
\hline & 6000,000 & 14,250 & 14,250 & 14,250 & 12,750 & 12,750 & 12,750 \\
\hline & 7020,000 & 12,750 & 12,750 & 12,750 & 12,000 & 11,250 & 11,250 \\
\hline & 7980,000 & 12,000 & 11,250 & 11,250 & 9,750 & 9,750 & 9,750 \\
\hline & 9000,000 & 9,000 & 9,750 & 9,750 & 9,750 & 9,000 & 8,250 \\
\hline & 10020,000 & 8,250 & 8,250 & 8,250 & 8,250 & 8,250 & 8,250 \\
\hline & 10200,000 & 6,000 & 6,000 & 6,000 & 6,000 & 6,000 & 6,000 \\
\hline & & \multicolumn{6}{|c|}{ TPS position [\%] } \\
\hline & & 59,250 & 60,000 & 69,000 & 74,250 & 84,000 & \\
\hline \multirow{16}{*}{ 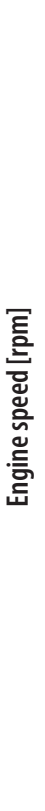 } & 780,000 & 9,000 & 9,000 & 9,000 & 9,000 & 9,000 & \\
\hline & 1200,000 & 9,000 & 9,000 & 9,000 & 9,000 & 9,000 & \\
\hline & 1980,000 & 9,000 & 9,000 & 9,000 & 9,000 & 9,000 & \\
\hline & 2460,000 & 9,000 & 9,000 & 9,000 & 9,000 & 9,000 & \\
\hline & 3000,000 & 15,000 & 15,000 & 15,000 & 15,000 & 15,000 & \\
\hline & 3540,000 & 18,000 & 18,000 & 18,000 & 17,250 & 17,250 & \\
\hline & 4020,000 & 18,000 & 18,000 & 17,250 & 17,250 & 15,750 & \\
\hline & 4500,000 & 17,250 & 17,250 & 17,250 & 15,750 & 14,250 & \\
\hline & 4980,000 & 15,750 & 15,000 & 15,000 & 12,750 & 12,750 & \\
\hline & 5520,000 & 14,250 & 12,750 & 12,750 & 11,250 & 11,250 & \\
\hline & 6000,000 & 12,750 & 11,250 & 11,250 & 9,750 & 9,750 & \\
\hline & 7020,000 & 11,250 & 9,750 & 9,750 & 9,000 & 9,000 & \\
\hline & 7980,000 & 9,750 & 9,000 & 8,250 & 8,250 & 8,250 & \\
\hline & 9000,000 & 8,250 & 6,750 & 6,750 & 6,000 & 6,000 & \\
\hline & 10020,000 & 8,250 & 8,250 & 6,750 & 6,000 & 6,000 & \\
\hline & 10200,000 & 6,000 & 5,250 & 5,250 & 3,750 & 3,750 & \\
\hline
\end{tabular}



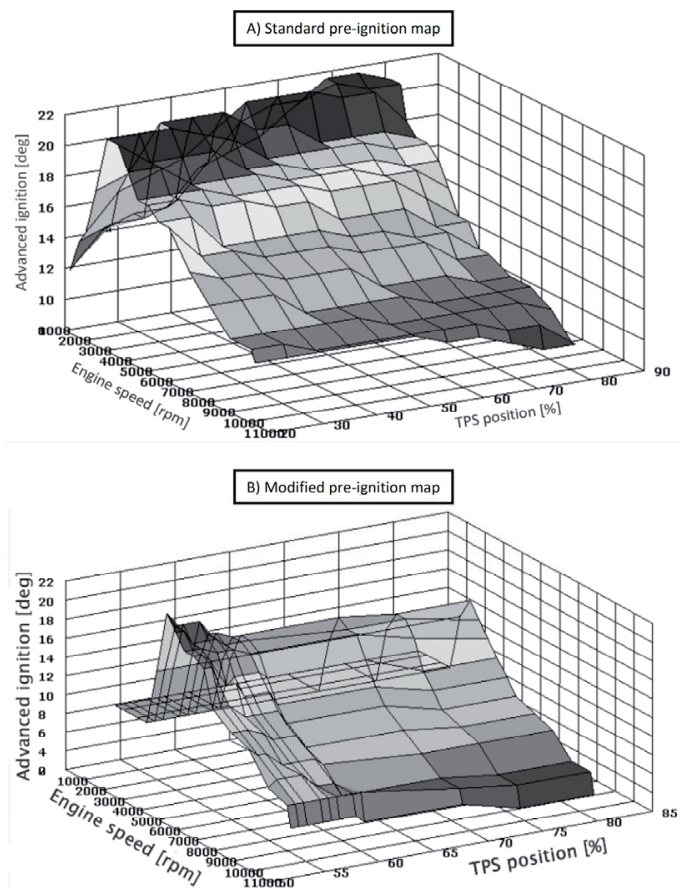

Fig. 4: 3D presentation of the standard and modified pre-ignition maps using the software ProCal.

set-up and subsequently it was tested after installation of the injection module and with the optimised data.

A large amount of the fuel maps and pre-ignition maps, which were applied during the whole tested process, served for determination of their optimal combination with regard to the minimal fuel consumption. There are presented in Tab. 5 the measured fuel consumption values in the case of the standard engine and modified engine.

Installation of the injection module and optimisation of the data fields have a positive influence on reduction of the fuel consumption and in this way the number of kilometres ridden with one litre of fuel was increased significantly, namely about $298 \mathrm{~km}$ in comparison with the standard

Table 5: Fuel consumption values before and after modification. engine application. Another relevant achievement, which represents a positive result of the described engine adjustments, is improvement of the engine operational flexibility and acceleration what is a very important advantage in the starting phase of the competition car [10, 11].

Determining the optimal combination of technical parameters during the test process has a decisive impact on various economic indicators: the number of kilometres travelled litre of fuel, fuel consumption per 100 kilometres, engine efficiency, engine running costs, engine maintenance costs, and engine wear and so on.

Optimization has a positive impact on fuel consumption per 100 kilometres. Consumption decreased from 0.74 litres per 100 kilometres to 0.23 . Under experimental conditions, there are no economic benefits that are crucial, but in practice, there have been significant savings in fuel costs.

In further research, it would be interesting to track the change in engine maintenance costs, wear at higher speeds and a few more times. Also interesting is the impact of possible additional costs associated with engine operation, such as frequent oil change.

The measuring equipment, which serves for recording of the $\lambda$-values during the engine operation, indicates an important fact that the engine is working with the lean fuel-air mixture $(\lambda>1)$ in the whole operational regime. This situation confirms a positive result that the performed engine modifications contributed to reduction of the exhaust gas emissions. Operation of engine in the rich working regime $(\lambda<1)$, i.e. with a redundancy of fuel, causes increasing of the carbon monoxide emissions (CO) and hydrocarbons emissions ( $\mathrm{HC}$ ) due to insufficiency of oxygen, because the rich fuel-air mixture is combusted incompletely.

The minimal values of the $\mathrm{HC}$ emissions are reached in the case that the $\lambda$-value is from the interval $1.1 \div 1.2$. Values of the nitrogen oxides emissions (NOx) are decreasing in the lean mixture area because the combustion temperature is

\begin{tabular}{|c|c|c|c|c|c|c|c|}
\hline $\begin{array}{l}\text { Number of } \\
\text { measuring }\end{array}$ & $\begin{array}{l}\text { Standard engine } \\
(\mathrm{km})\end{array}$ & $\begin{array}{l}\text { Optimised } \\
\text { engine (km) }\end{array}$ & Difference & $\begin{array}{l}\text { Standard max. } \\
\text { speed }(\mathrm{km} / \mathrm{h})\end{array}$ & $\begin{array}{l}\text { Optimised max. } \\
\text { speed }(\mathrm{km} / \mathrm{h})\end{array}$ & $\begin{array}{l}\text { Standard } \\
\text { consumption } \\
\text { (1/100km) }\end{array}$ & $\begin{array}{l}\text { Optimised } \\
\text { consumption } \\
(1 / 100 \mathrm{~km})\end{array}$ \\
\hline 1. & 140 & 426 & 286 & 38 & 43 & 0.71 & 0.23 \\
\hline 2. & 131 & 415 & 284 & 35 & 41 & 0.76 & 0.24 \\
\hline 3. & 135 & 433 & 298 & 35 & 42 & 0.74 & 0.23 \\
\hline
\end{tabular}




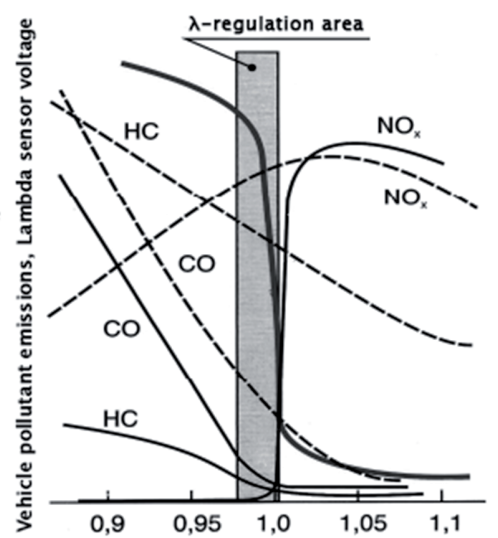

Fig. 5: Composition of emissions depending on the $\lambda$-value.

reduced during the engine operation in the lean working regime (Fig. 5) [12].

\section{Conclusions}

The research and development, which was performed in the area of the driving unit adjustment, resulted in a significant reduction of the fuel consumption compared to the standard motormanagement system. The engine speed level was increased thanks to a suitable modification of the engine control unit and in this way there was also heightened the maximal value of the experimental vehicle speed.

Optimisation of the driving unit improved the combustion process in order to reach higher level of the fuel consumption efficiency with a positive influence on the environment due to reduction of the carbon oxide emissions. The results of our research work were introduced also internationally, namely at the international competition Shell Ecomarathon in London.

\section{Acknowledgments}

The article was written in the framework of Grant Projects: APVV16-0259"Research and development of combustion technology based on controlled homogenous charge compression ignition in order to reduce nitrogen oxide emissions of motor vehicles", VEGA 1/0473/17 "Research and development of technology for homogeneous charge self-ignition using compression in order to increase engine efficiency and to reduce vehicle emissions" and KEGA 041TUKE4/2017 "Implementation of new technologies specified for solution of questions concerning emissions of vehicles and transformation of them into the educational process in order to improve quality of education."

\section{References and Notes}

[1] PUŠKÁR, M.; BIGOŠ, P.: Method for accurate measurements of detonations in motorbike high speed racing engine, Measurement 2012, Vol. 45, no. 3 (2012), p. 529-534, ISSN 0263-2241

[2] PUŠKÁR, M.; BIGOŠ, P.; PUŠKÁROVÁ, P.: Accurate measurements of output characteristics and detonations of motorbike high-speed racing engine and their optimization at actual atmospheric conditions and combusted mixture composition, Measurement 2012, Vol. 45, no. 5 (2012), p. 1067-1076, ISSN 0263-2241

[3] PUŠKÁR, M.; BIGOŠ, P.; BALÁŽIKOVÁ, M.; PEŤKOVÁ, V:: The measurement method solving the problems of engine output characteristics caused by change in atmospheric conditions on the principle of the theory of optimal temperature range of exhaust system, Measurement 2012, In Press, ISSN 0263-2241

[4] PUŠKÁR, M. ... [et al.]: Measuring method for feedback provision during development of fuel map in hexadecimal format for high-speed racing engines, In: Measurement. Vol. 50, no. 1 (2014), p. 203-212. - ISSN 0263-2241

[5] Hiroyuki Yamada, Rumiko Hayashi, Kenichi Tonokura : Simultaneous measurements of on-road/in-vehicle nanoparticles and NOx while driving: Actual situations, passenger exposure and secondary formations, Science of The Total Environment, Volumes 563-564, 1 September 2016, Pages 944-955

[6] Xiangyu Feng, Yunshan Ge, Chaochen Ma, Jianwei Tan, Xin Wang Experimental study on the nitrogen dioxide and particulate matter emissions from diesel engine retrofitted with particulate oxidation catalyst, Science of The Total Environment, Volume 472, 15 February 2014, Pages 56-62

[7] PUŠKÁR, M., BRESTOVIČ, T., JASMINSKÁ, N. Numerical simulation and experimental analysis of acoustic wave influences on brake mean effective pressure in thrust-ejector inlet pipe of combustion engine. In: International Journal of Vehicle Design. Vol. 67, no. 1 (2015), p. 63-76. - ISSN 0143-3369

[8] SINAY, J. et al. (2014) Multiparametric Diagnostics of Gas Turbine Engines. The Transactions of RINA, Vol 156, Part A2, International Journal of Maritime Engineering, 2014, p. 149-156, ISSN 1479-8751

[9] Balland, O.; Erikstad S. O.; Fagerholt, K.: Concurrent design of vessel machinery system and air emission controls to meet future air emissions regulations, Ocean Engineering, Volume 84, 1 July 2014, Pages 283-292

[10] PUŠKÁR, M.; BIGOŠ, P.: Output Performance Increase of Two-stroke Combustion Engine with Detonation Combustion Optimization, Strojarstvo 2010: Vol. 52, no. 5 (2010), p. 577-587, ISSN 0562-1887

[11] PUŠKÁR, M.; BIGOŠ, P. Measuring of acoustic wave influences generated at various configurations of racing engine inlet and exhaust system on brake mean effective pressure, Measurement 46 (9) (2013) 3389-3400. ISSN 0263-2241.

[12] Czech P. Application of probabilistic neural network and vibration signals for gasket under diesel engine head damage. Scientific Journal of Silesian University of Technology. Series Transport. 2013. Vol. 78. P. 39-45. ISSN: 0209-3324 